\title{
The impact of species and cell type on the nanosafety profile of iron oxide nanoparticles in neural cells
}

\author{
Freya Joris ${ }^{1}$ (D), Daniel Valdepérez ${ }^{2}$, Beatriz Pelaz ${ }^{2}$, Stefaan J. Soenen ${ }^{3}$, Bella B. Manshian ${ }^{3}$, Wolfgang J. Parak², \\ Stefaan C. De Smedt ${ }^{1 * \dagger}$ and Koen Raemdonck ${ }^{1 \dagger}$
}

\begin{abstract}
Background: While nanotechnology is advancing rapidly, nanosafety tends to lag behind since general mechanistic insights into cell-nanoparticle (NP) interactions remain rare. To tackle this issue, standardization of nanosafety assessment is imperative. In this regard, we believe that the cell type selection should not be overlooked since the applicability of cell lines could be questioned given their altered phenotype. Hence, we evaluated the impact of the cell type on in vitro nanosafety evaluations in a human and murine neuroblastoma cell line, neural progenitor cell line and in neural stem cells. Acute toxicity was evaluated for gold, silver and iron oxide (IO)NPs, and the latter were additionally subjected to a multiparametric analysis to assess sublethal effects.
\end{abstract}

Results: The stem cells and murine neuroblastoma cell line respectively showed most and least acute cytotoxicity. Using high content imaging, we observed cell type- and species-specific responses to the IONPs on the level of reactive oxygen species production, calcium homeostasis, mitochondrial integrity and cell morphology, indicating that cellular homeostasis is impaired in distinct ways.

Conclusions: Our data reveal cell type-specific toxicity profiles and demonstrate that a single cell line or toxicity end point will not provide sufficient information on in vitro nanosafety. We propose to identify a set of standard cell lines for screening purposes and to select cell types for detailed nanosafety studies based on the intended application and/or expected exposure.

Keywords: Nanosafety, High content imaging, Inorganic nanoparticles, Iron oxide nanoparticles, Stem cells, Multiparametric analysis

\section{Background}

In recent years, many inorganic nanoparticles (NPs) have made their way to the market as they are being incorporated into various consumer products [1]. Moreover, their unique properties are being extensively explored for various biomedical applications. For instance, gold NPs (AuNPs) and iron oxide NPs (IONPs) hold great promise

\footnotetext{
*Correspondence: stefaan.desmedt@ugent.be

'Stefaan C. De Smedt and Koen Raemdonck contributed equally to this work

${ }^{1}$ Lab of General Biochemistry and Physical Pharmacy, Department of Pharmaceutics, Faculty of Pharmaceutical Sciences, Ghent University, Ottergemsesteenweg 460, 9000 Ghent, Belgium

Full list of author information is available at the end of the article
}

as theranostic agents for cancer treatment through hyperthermia combined with tumour detection via respectively photoacoustic or magnetic resonance imaging [2]. Additionally, silver NPs (AgNPs) are good candidates for wound dressings and antibacterial coatings of medical devices due to their enhanced antimicrobial properties [3]. However, to date only a few nano-enabled products were successfully translated into the clinic. Besides general targeting issues, this can primarily be attributed to their elusive safety profiles [4]. Despite extensive efforts, a general paradigm on how inorganic NPs are able to affect homeostasis on the level of the cell, organ or organism and to which physicochemical NP properties this can be attributed, is largely lacking [5]. 
In general, nanosafety evaluations struggle with two important obstacles. The first is the fast pace at which nanotechnology keeps advancing, leading to the development of a plethora of NPs with distinct physicochemical properties, which should ideally undergo safety evaluation prior to their (biomedical) implementation. The second is the lack of standardization of in vitro nanosafety studies, as various groups apply different assays on various cell types. This results in low inter-study comparability and the publication of conflicting data, which complicates the elucidation of general paradigms on NPcell interactions $[6,7]$.

The first hurdle can be overcome by implementing high throughput or high content techniques in order to speed up in vitro nanosafety testing $[8,9]$. Secondly, much effort is being put into the standardization of various factors of in vitro nanosafety studies $[10,11]$. In this regard, we believe that the cell type selection should receive equal attention. In most studies a cell line is selected since they are in general more readily accessible, less expensive and easier to cultivate when compared to primary cells $[7,12]$. However, cancer cell lines have a disturbed antiapoptotic balance as well as an altered metabolism to sustain their high proliferation rate [13]. The phenotype expressed by immortalized cells is in turn not entirely stable and might undergo changes due to the extensive in vitro manipulation or the initial immortalization [14]. Hence, a shift towards the use of primary or stem cells as well as more complex cell culture models for in vitro nanosafety testing strategies could be noted recently. In contrast, primary cells can suffer from clonal variations and have a limited lifespan in vitro, making rational cell type selection a balancing act [7].

Subsequent to the realization that the cell type could be of substantial importance, several groups have shown that NP-induced effects vary in cell lines retrieved from different tissues or species [15-18]. On the contrary, only a few studies compared NP effects in a cancer or immortalized cell line versus primary cells representing the same tissue and species $[19,20]$. Unfortunately, available data contrast one another wherefore no unambiguous conclusions could yet be formulated on whether cell lines can generally be applied as a reliable model for in vitro nanosafety studies. In addition, many of the abovementioned reports choose to either focus on interspecies variations or cell-type related differences in NP-evoked effects and do not address both factors in a single study.

Here, we present a side-by-side comparison of NPevoked effects in six related neural cell types thereby evaluating the extent of both species and cell type related variations in NP-induced cytotoxicity. We selected a neuroblastoma cell line, neural progenitor cell line and neural stem cells derived from either humans or mice (Table 1 )
Table 1 Cell types applied in this study

\begin{tabular}{llll}
\hline & Stem cells & Progenitor cell line & Cancer cell line \\
\hline Human & hNSC [26] & ReNcell [27] & LA-N-2 [28] \\
Mouse & mNSC [26] & C17.2 [29] & Neuro-2a [30] \\
\hline
\end{tabular}

and purposely applied the optimal culture conditions for each cell type. These cell types were selected as potential models to assess the safety of neural stem cell labeling with nanosized contrast agents prior to transplantation in the context of regenerative medicine [21-23]. In turn, the synthesized AuNPs, AgNPs and IONPs had a diameter below $10 \mathrm{~nm}$, making them good candidates for the proposed application [24]. First, we surveyed the acute toxicity of AuNPs, AgNPs and IONPs in all cell types. Subsequently we selected the IONPs for further evaluation given the minor acute toxicity. Hereto we applied a validated multiparametric approach, using automated imaging, to evaluate the effect of sublethal doses on the production of reactive oxygen species (ROS), the calcium $\left(\mathrm{Ca}^{2+}\right)$ homeostasis, mitochondrial health and cell morphology [25]. Importantly, our data reveal distinct and cell type specific toxicity profiles that warrant careful selection of appropriate cell models for future nanosafety studies, taking both species and target tissue into account, and caution misinterpretation of experimental results based on a single cell type and/or toxicity end point.

\section{Results and discussion}

\section{Synthesized inorganic NPs display similar physicochemical} characteristics

AuNP, AgNP and IONP synthesis was initiated with the aim of obtaining a similar core diameter. All NPs had a mean core diameter around $3.8 \mathrm{~nm}$, as measured by transmission electron microscopy (Additional file 1: Figure S4). Subsequently all NPs were coated with poly(isobutylene-alt-maleic anhydride) grafted with dodecylamine (PMA), which was selected as it ensures colloidal stability over a wide $\mathrm{pH}$ range and a uniform coating of the different core materials [31]. Dynamic light scattering measurements in water showed a hydrodynamic diameter of 9.0, 8.9 and $12.3 \mathrm{~nm}$ and a negative zeta-potential around $-45,-35$, and $-54 \mathrm{mV}$ for the coated AuNPs, AgNPs and IONPs respectively. All obtained values correspond well to data reported on the characterization of NPs synthesized via similar protocols $[32,33]$. The NPs were synthesized with the intention of obtaining similar physicochemical properties so that discrepancies in cell responses could be related to variations between the cell types. Additional characterization data on the plasmon resonance peaks, molecular extinction coefficients, initial NP dispersion concentrations, and 


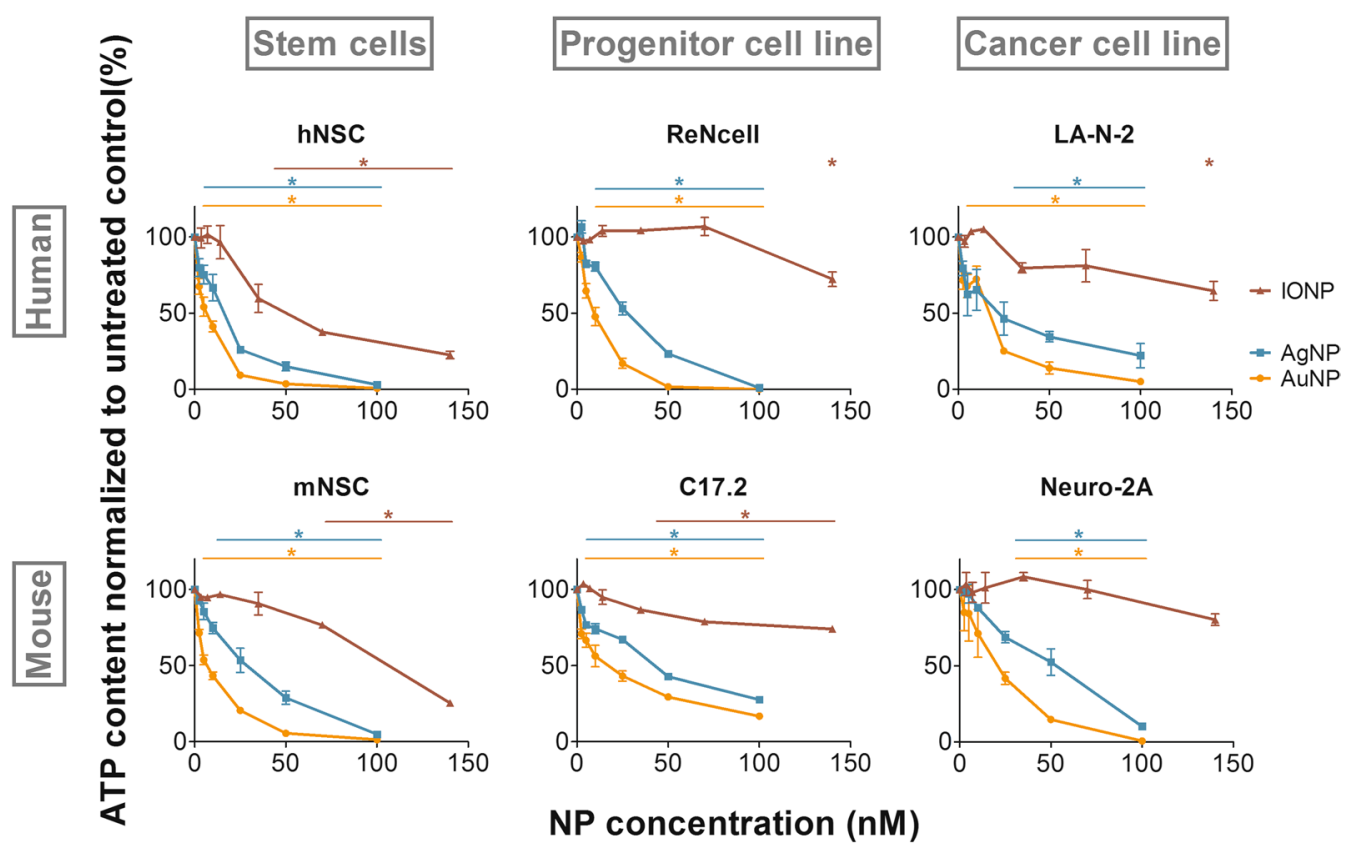

Fig. 1 A concentration-dependent decrease in ATP content, as measured via the CellTiter GLO ${ }^{\circledR}$ assay, is observed for every NP-cell type combination tested. Results for the AuNPs (yellow), AgNPs (blue) and IONPs (red) are represented as mean \pm standard error of the mean (SEM, $n=3$,). Statistical significance is indicated when appropriate for each type of NP in the corresponding color of the graphs [* $<0.05$, AuNPs (yellow), AgNPs (blue) and IONPs (red)]

electrophoretic mobility can be found in Additional file 1: Figures S5, S6 and Tables S1, S2.

\section{Acute toxicity depends on both the NP core material and the cell type}

In initial cell experiments, we evaluated cell viability following $24 \mathrm{~h}$ NP exposure with the CellTiter GLO ${ }^{\circledR}$ assay. In Fig. 1, a general concentration-dependent decrease in ATP signal can be observed for every evaluated $\mathrm{NP}$-cell type combination. Although the extent of this decrease clearly varies, the onset of this downward trend depended on both the applied NP and the cell type. In all cell types, the most severe effect was observed following AuNP treatment, while the cells were least affected by the IONPs. The toxicity observed for the AgNPs can likely in part be explained in terms of $\mathrm{Ag}^{+}$-ion leaching [34]. In turn, the severe acute cytotoxicity induced by the AuNPs could possibly be attributed to genotoxicity due to direct interactions between the $3.8 \mathrm{~nm}$ diameter AuNPs and DNA [35]. In addition, note that determining NP concentrations is not straightforward, as various methods/ models need to be applied for different NP materials (Additional file 1). This may affect the comparison of absolute concentrations of NPs of different materials and may additionally explain the severe toxicity observed here for the AuNPs. Given the limited loss of cell viability observed for the IONPs, the latter were selected for further evaluation of sublethal effects.

Independent of the core material, the Neuro-2a cells were least susceptible to NP exposure whereas the hNSC, followed by the mNSC, were most sensitive. The susceptibility ranking for the other cell types varied with the NP core material. This greater sensitivity of the NSC, as found under the conditions reported here, is dissimilar to several studies where cell lines were found to be more susceptible to NP-induced acute cell injury [18, 19]. However, our data correlate well with previous work from Bregoli et al. [14] who did not observe any toxic effects in several hematopoietic cell lines, while primary bone marrow cells were clearly affected. Similar observations were recorded by Wilkinson et al. and Schlinkert et al. who independently found normal bronchial epithelial cells to experience more acute toxicity than the A549 cancer cell line [36, 37].

\section{ROS induction is observed in two out of six cell types}

Since we found the IONPs to induce the least acute cell damage, it was decided to probe for sublethal effects caused by these NPs using a multiparametric methodology. The evaluation of effects on cell function has become crucial, as it is generally recognized that nanosafety evaluations should go beyond live/dead scoring in order 
to establish a more predictive paradigm $[15,38]$. Subtle changes in cell function might indeed be more predictive towards in vivo adverse outcomes. For instance, NPpromoted reactive oxygen species (ROS) production in pulmonary cells has been linked to acute inflammation in the lung $[39,40]$. ROS induction is also stated to be the main mechanism via which metallic NPs induce cell stress. Persisting ROS induction can subsequently lead to oxidative stress and damage cellular components such as DNA, proteins and membrane lipids [6].

Upon IONP treatment, we observed an increased ROS production in two out of six cell types, namely the mNSC and human ReNcells (Fig. 2). In all other four cell types, ROS production was significantly reduced. Notably, for both the reduced or increased ROS levels, the effect was most outspoken in the NSC. Again the murine neuroblastoma cell line (Neuro-2a) was least affected in terms of ROS. Given the variable effects, no general statements can be made on whether the human or murine cell types were more severely affected than their counterparts.

Although ROS induction by IONPs is often observed $[19,39,41]$, it has been shown that NP-induced cytotoxicity cannot always be attributed to an increased ROS production [42]. Interestingly, Harris et al. also witnessed reduced ROS levels in their high content analysis of IONP-induced effects on a mammalian fibroblast cell line [6]. Additionally, IONPs can exhibit an intrinsic peroxidase-like activity in mesenchymal stem cells and thus reduce the cellular ROS content, especially of $\mathrm{H}_{2} \mathrm{O}_{2}$ $[43,44]$. As this effect was only witnessed when IONPs remained intact, IONP biocompatibility is presumably to a large extent affected by the intracellular location and the way the cell processes the IONPs. In confirmation, Sabella et al. [45] found greater cell perturbation by metallic NPs when they were trafficked to the acidic lysosomes in comparison to the same NPs present in the cytoplasm, due to the enhanced degradation in the acidic compartments. Indeed, this degradation will be accountable for an increased amount of free iron ions, which may in turn enhance ROS production via for instance Fenton chemistry $[6,46]$. A final factor that could clarify our observation is the intrinsically different anti-oxidative capacity of the various cell types $[15,17]$. Thus, the cell itself likely determines NP biocompatibility to a large extent.

\section{IONP exposure perturbs cellular calcium homeostasis}

Subsequently, we evaluated the effect of IONP exposure on the $\mathrm{Ca}^{2+}$ homeostasis. The intracellular free $\mathrm{Ca}^{2+}$ concentration $\left(\left[\mathrm{Ca}^{2+}\right]_{\mathrm{c}}\right)$ is a valuable toxicity marker since $\mathrm{Ca}^{2+}$ is involved in a plethora of processes such as cell proliferation, mitochondrial function and gene

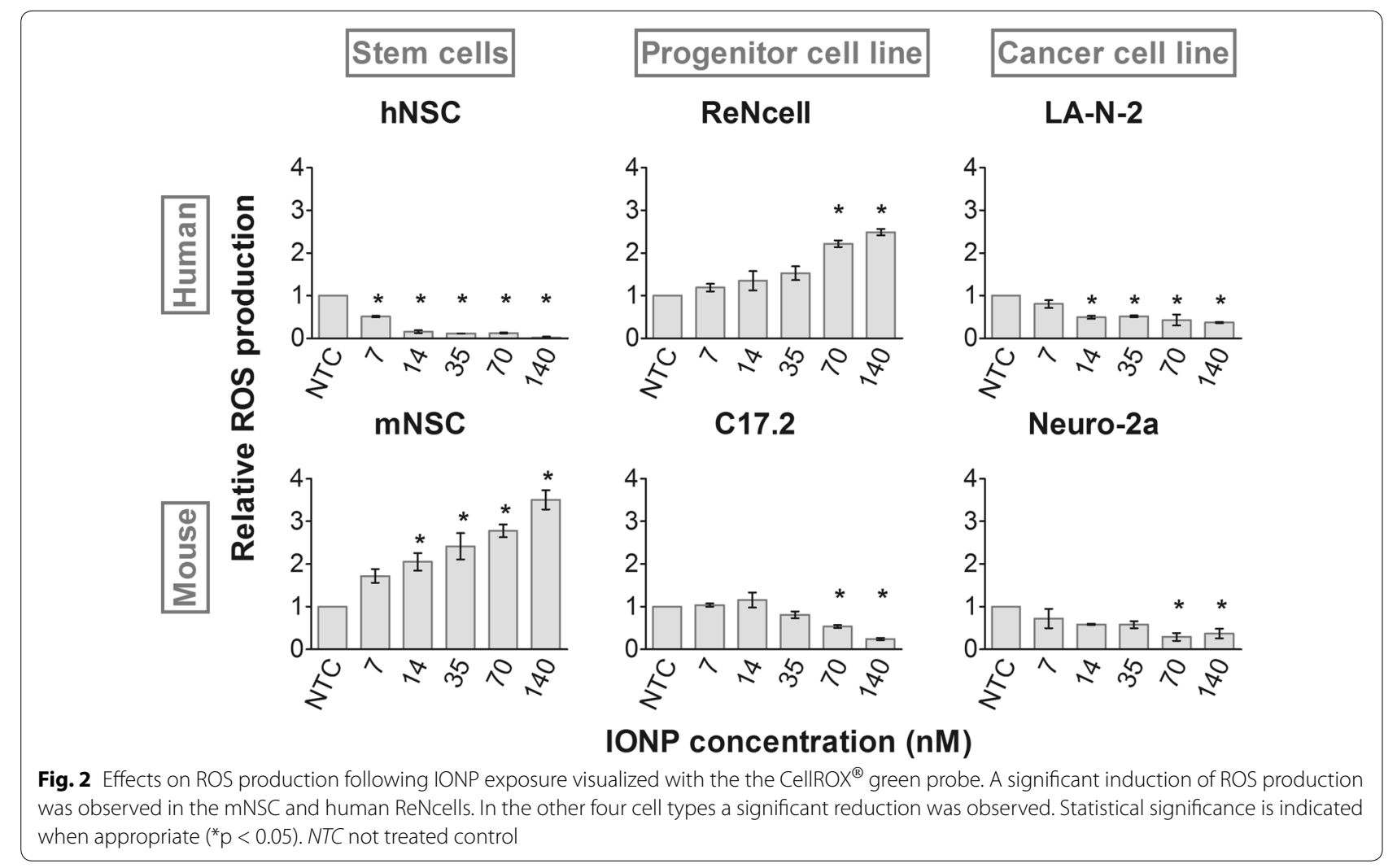


expression $[47,48] . \mathrm{Ca}^{2+}$ is furthermore of ultimate importance for proper cell function in neural cells, as it is required for neurotransmitter release and cellular excitability $[8,49]$. Additionally, $\mathrm{Ca}^{2+}$ is since long known to be an important regulator of cell death, where a significant increase in $\left[\mathrm{Ca}^{2+}\right]_{\mathrm{C}}$ is noted [47]. A mild reduction can on the contrary be correlated with an impaired cell function due to enhanced intracellular $\mathrm{Ca}^{2+}$ storage or efflux in an effort to retain cell homeostasis, while cell lysis is correlated to a more severe decrease $[48,50]$.

On the one hand, a significant concentration-dependent increase in $\left[\mathrm{Ca}^{2+}\right]_{\mathrm{c}}$ was observed in the hNSC, ReNcells, and C17.2 cells (Fig. 3). The effect was more severe in the progenitor cell lines compared to the hNSC and the ReNcells showed the highest $\left[\mathrm{Ca}^{2+}\right]_{\mathrm{c}}$. On the other hand, a decline of the $\left[\mathrm{Ca}^{2+}\right]_{\mathrm{c}}$ was detected in the mNSC, LA-N-2 and Neuro-2a cells. In contrast to previous parameters, the Neuro-2a cells showed more severe effects in terms of the perturbation of the calcium homeostasis. Again, no unambiguous conclusions could be drawn on whether human or murine cell types are more sensitive towards NP exposure.

Multiple studies investigating the influence of NP exposure on the $\mathrm{Ca}^{2+}$ homeostasis also found $\left[\mathrm{Ca}^{2+}\right]_{\mathrm{C}}$ to be augmented [51]. Since this response could be interpreted as a cell death signal, this outcome could be correlated to the initially observed acute toxicity (Fig. 1) $[47,52]$. Although we would have expected to observe a greater increase in $\left[\mathrm{Ca}^{2+}\right]_{\mathrm{c}}$ in the hNSC when compared to the ReNcells based on the acute toxicity data, the opposite was true. In line with the observed decline in $\left[\mathrm{Ca}^{2+}\right]_{\mathrm{c}}$ in three out of six cell types, Haase et al. [3] documented diminished $\mathrm{Ca}^{2+}$ responses at cytotoxic NP doses in mNSC. This observation could on the one hand be explained in terms of cell lysis. On the other hand, stressed cells can maintain their $\mathrm{Ca}^{2+}$ homeostasis by elevating $\mathrm{Ca}^{2+}$ efflux via the plasma membrane $\mathrm{Ca}^{2+}$ ATPase pump [50]. We hypothesized that this occurred in the neuroblastoma cell lines where ATP levels were to a minor extent reduced and thus still allowed sufficient pump function.

In general, two groups could be distinguished based on the elevation or diminution of $\left[\mathrm{Ca}^{2+}\right]_{\mathrm{c}^{*}}$. Even though similar trends were retrieved in each group, it is clear that the extent of the perturbation of cellular $\mathrm{Ca}^{2+}$ homeostasis varied with the cell type. Since $\mathrm{Ca}^{2+}$ homeostasis is significantly altered upon cell transformation or immortalization in favour of cell proliferation [53], it was not surprising that NP exposure variably altered the $\left[\mathrm{Ca}^{2+}\right]_{\mathrm{c}}$. Notably, cell type specific toxicity profiles started to emerge as various combinations of the thus far evaluated effects were obtained.

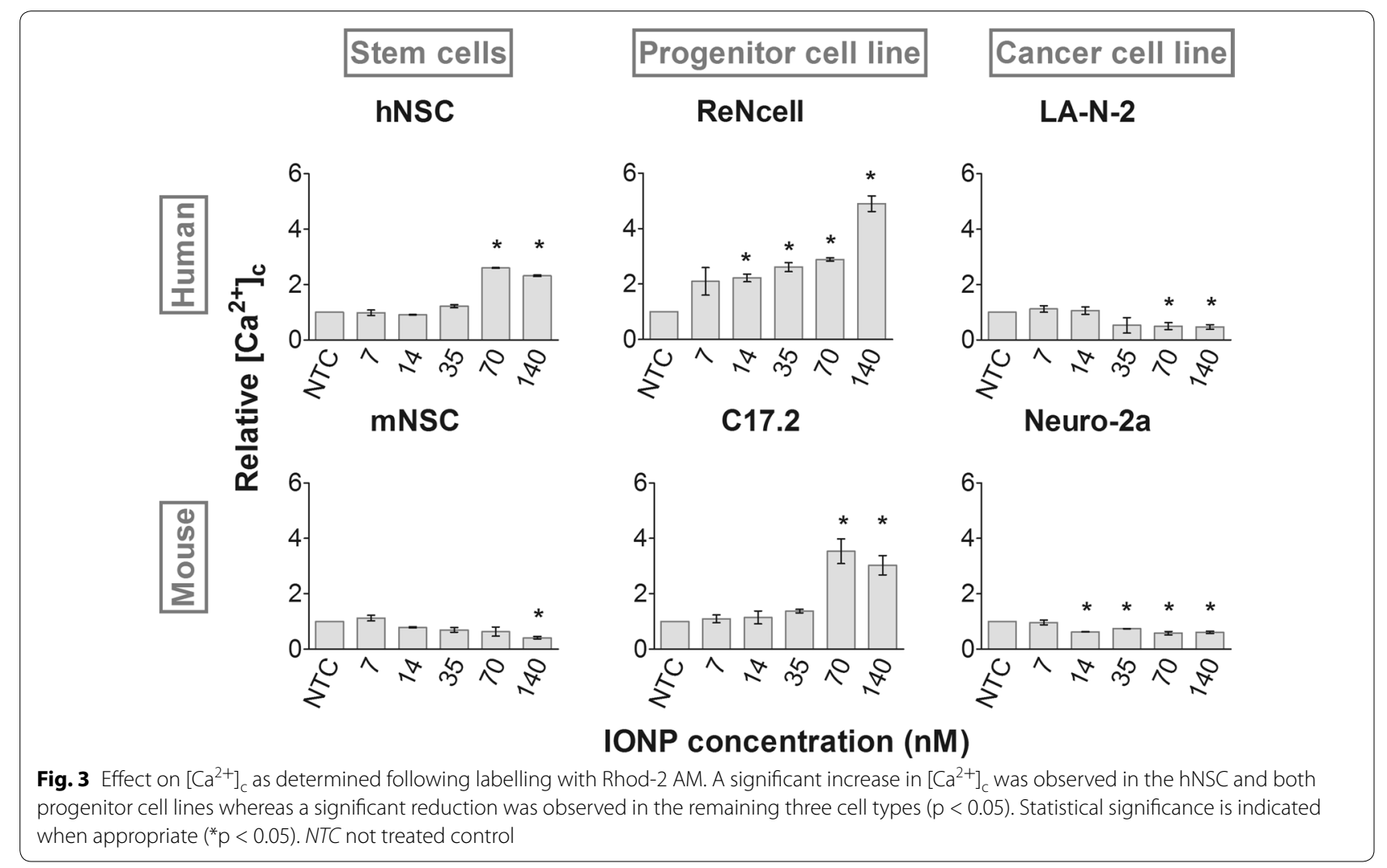




\section{Mitochondria are affected by IONP loading}

Next, the effect of IONP exposure on mitochondrial homeostasis was evaluated. The mitochondria are interesting organelles as they are the cell's main energy suppliers, involved in programmed cell death, an important source of ROS and to a large extent regulated by $\mathrm{Ca}^{2+}[52$, 54]. This $\mathrm{Ca}^{2+}$-mediated regulation is furthermore influenced by external stimuli: in combination with a stress inducer $\mathrm{Ca}^{2+}$ promotes ROS production and possibly cell death, whereas under physiological conditions $\mathrm{Ca}^{2+}$ stimulates the oxidative respiration in the mitochondria and thus ATP production [52]. Interestingly, the importance of oxidative respiration for overall cellular ATP production varies with the cell type: both cancer cells and stem cells rather rely on cytosolic glycosylation for their ATP production [54, 55]. Hence, it is conceivable that mitochondria will not only be differentially affected, but also that the impact of mitochondrial perturbation on overall cell homeostasis will vary in the different cell types.

To visualize the mitochondria, we selected a probe that specifically labels the organelles based on their membrane potential $\left(\Delta \Psi_{\mathrm{m}}\right)$. Loss of this potential, as a result of mitochondrial membrane permeabilization, will render the organelle undetectable and has been associated with cytochrome $\mathrm{C}$ release and cell death initiation [52,
56]. During data analysis, such events could be detected as a reduction of the relative mitochondrial area. Figure 4 shows that all cell types, except the Neuro-2a cells, showed significant mitochondrial damage. Accordingly, the loss of $\Delta \Psi_{\mathrm{m}}$ following NP exposure has already been described in multiple studies for several NPs in cell types from various lineages and species $[8,9,42]$. In the NSC all IONP doses caused a decreased signal area, though the effect was only significant starting from $7 \mathrm{nM}$. In contrast, the affected cell lines (ReNcell, C17.2 and LA-N2) were significantly affected by all IONP doses. The effects were most outspoken in the ReNcells, closely followed by the hNSC and mNSC. The mitochondria in the C17.2 and LA-N-2 cell lines were perturbed to a lesser extent. Notably, the human cell types were more severely affected than the murine counterpart. In addition, the neuroblastoma cell lines were most resilient on the mitochondrial level. In correspondence, Heerdt et al. [57] have previously found mitochondria in transformed cells to be less sensitive to perturbation due to an intrinsically lower mitochondrial activity and higher $\Delta \Psi_{\mathrm{m}}$.

\section{IONP loading affects cell morphology}

Lastly, we examined alterations in cell morphology following IONP exposure. Cell morphology is a convenient

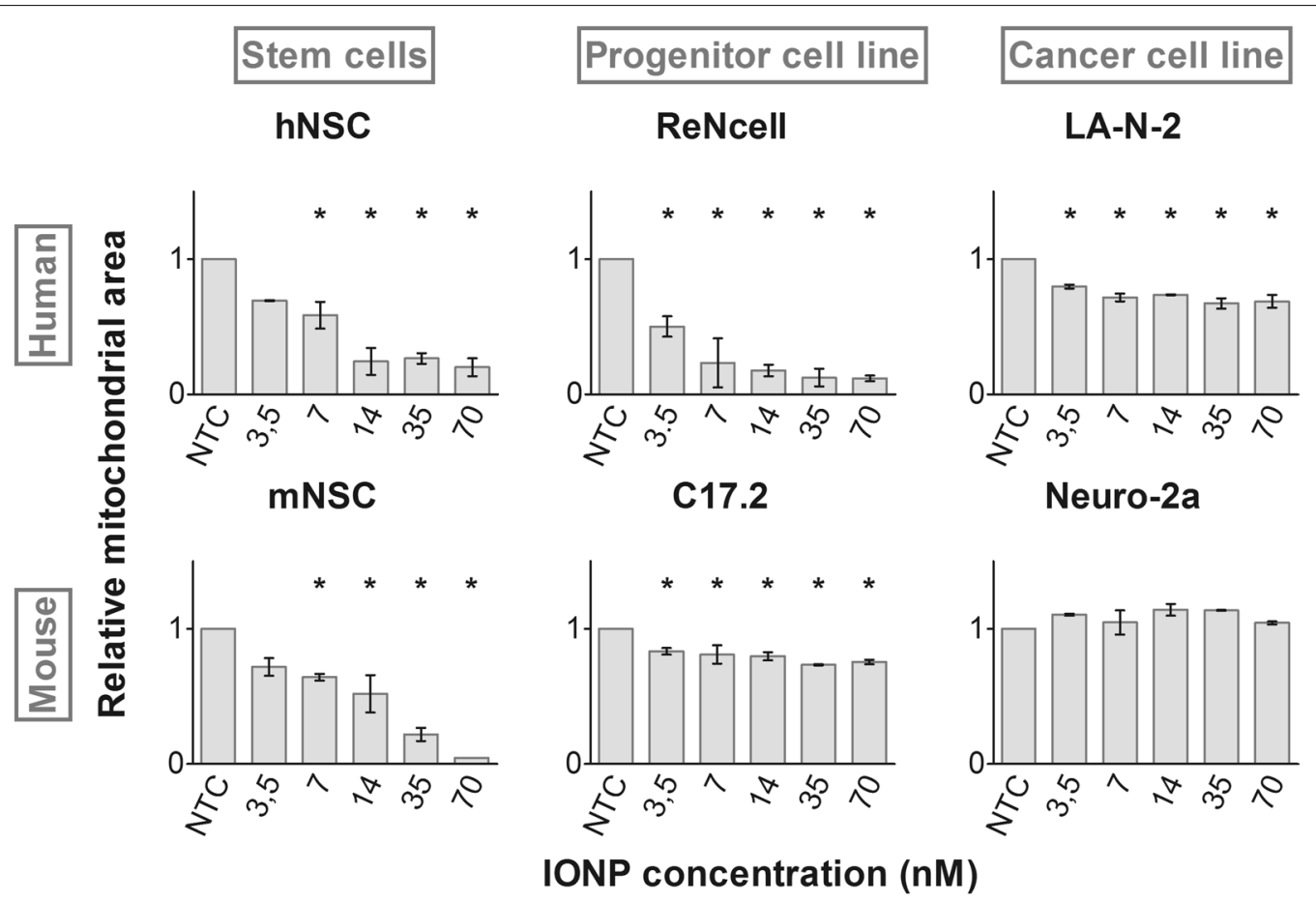

Fig. 4 Effects on the mitochondria labelled with Mitotracker ${ }^{\circledR} C M X-R O S$ in terms of the relative signal area representing the size of the mitochondrial compartment relative to the total cell area. Except for the Neuro-2a cell line, all cell types showed a significant decrease in mitochondrial area. Statistical significance is indicated when appropriate $\left({ }^{*} p<0.05\right)$. NTC not treated control 
parameter, especially for neural cells given their intricate architecture [8]. Moreover, numerous NPs have been shown to alter cell morphology as a secondary effect of ROS induction or via direct interactions with elements of the cytoskeleton $[58,59]$. In addition to the changes in the morphological appearance, certain cell functions that require signaling via these components can subsequently be impaired $[59,60]$. Thus, subtle effects on cell morphology can indirectly herald perturbation of cell function whereas severe morphological alterations, i.e. cell rounding and shrinking, can be interpreted in terms of cell death [47].

After staining the entire cell cytoplasm, the impact of IONP exposure on cell morphology was quantified via two parameters: cell area and cell circularity. The latter is applied as a measure of cell spreading and is a value between zero and one, where one represents a perfect sphere (Additional file 1). Although the extent of neurite outgrowth is often applied to evaluate the morphology of neural cells [61], this parameter was not selected for this work, as several cell types are not capable of forming neurites.

While only a significantly decreased cell area was noted for the C17.2 cell line, both a reduced cell area and an increase in circularity were observed in the
NSC, ReNcells and Neuro-2a cells (Fig. 5; Additional file 1: Figure S8). Thus, the cells became both smaller and more spherical in a concentration-dependent fashion (Fig. 6), which was most outspoken in the ReNcells. Such loss of specific morphological features and cell shrinking has already been described in numerous studies for multiple NPs and cell types [3, 8, 22, 42]. Since it is known that cell transformation or immortalization affects cell morphology, it is not surprising that morphology was also differentially affected in the various cell types. For instance the mNSCs were more strongly affected in terms of morphology whereas only minor effects were observed in the C17.2 or Neuro-2a cell line. Since stem cells have a more intricate architecture in comparison to most cell lines, it was not surprising that the morphology of the former was impaired more extensively. Finally, as the LA-N-2 cells tend to grow in clusters we evaluated effects on cell morphology in terms of the total cluster area and number of cells per cluster, which both showed a similar concentration-dependent decrease starting from $3.5 \mathrm{nM}$ IONPs. Since the decrease in cluster area was slightly more severe than the number of cells per cluster, we concluded that the cell area also decreased with every dose tested.

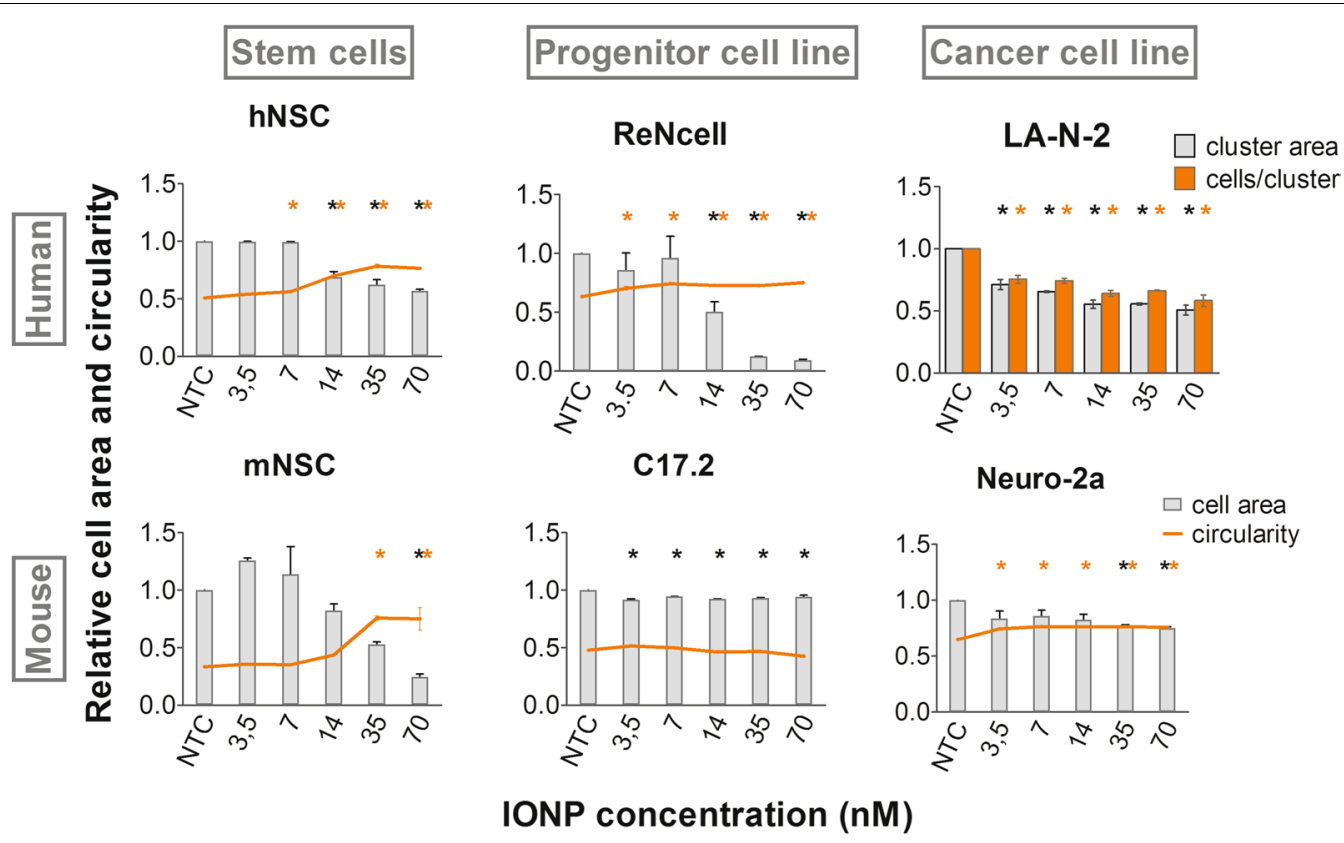

Fig. 5 IONP-induced alterations in cell area (grey bars) and cell circularity (orange lines) visualized after labelling of the cytoplasm with the CellMask ${ }^{\mathrm{TM}}$ Blue probe for the NSC, progenitor cell lines and murine neuroblastoma cell line. Cell circularity is a measure of cell spreading and is a value between zero and one, where one represents a perfect sphere. LA-N-2 cell morphology was analysed in terms of cluster area (grey bars) and number of cells per cluster (orange bars). A decreased cell area and increased cell circularity were detected in the NSC, ReNcell and Neuro-2a cell line. For the C 17.2 cells only a diminution in cell area was detected. In the LA-N-2 cell line a reduction in cells per cluster and cluster size were observed. Statistical significance is indicated when appropriate $\left({ }^{*} p<0.05\right)$, in black for the cell area and orange in case of the cell circularity (respectively cluster area and cells per cluster in case of the LA-N-2 cell line). NTC not treated control 


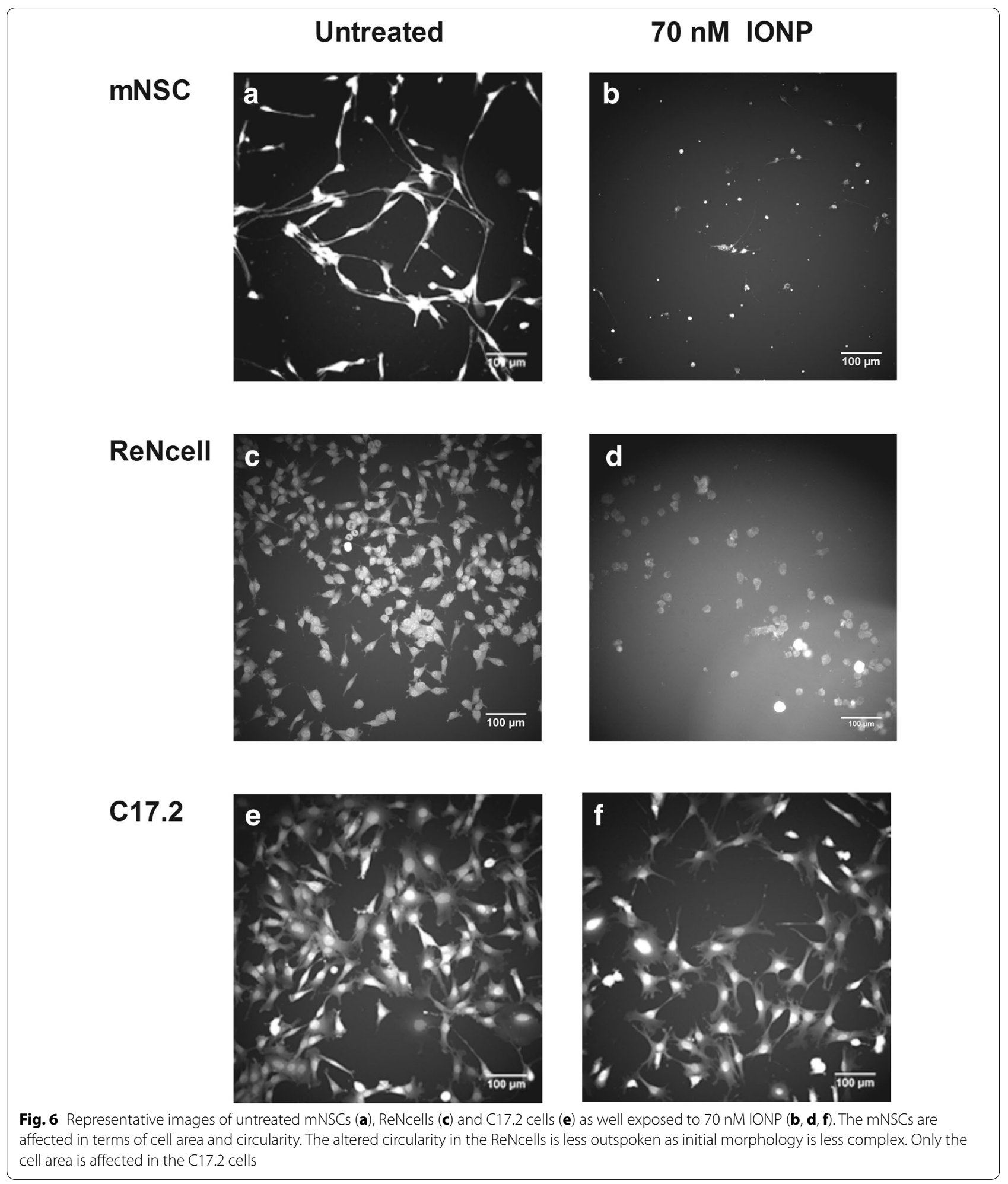

Overall, we observed similar effects on cell morphology (cell rounding and shrinking) in the various cell types in contrast to previously evaluated parameters.
However, the exact trends and extent of the responses clearly differed. Importantly, these variations could not unequivocally be linked to one or a specific combination 
of responses observed for the other toxicity parameters investigated in this study, underscoring the cell type specific nature of the recorded toxicity profiles.

\section{Multiparametric analysis reveals cell type-specific toxicity profiles}

In general, our data set reveals that each cell type reacted in a specific way to IONP exposure in terms of both extent and nature of the responses (Table 2). This could not have been deduced from the acute toxicity assessment (Fig. 1) but became increasingly clear with every additionally evaluated parameter. Furthermore, the obtained profiles would likely become increasingly complex with the addition of supplementary end points such as the influence on autophagy, induction of endoplasmic reticulum stress or genotoxicity. Note that it was not the primary objective of this study to unravel the underlying toxicity mechanisms. Hereto, additional experiments, for instance on the type of cell death or gene expression, should be performed. Instead, the aim was to clearly show the impact of both the species and the cell type, under its optimal cell culture conditions on the nanotoxicity profile within one single study. We show that for 3 different, though related neural cell types (stem cells, immortalized cells and cancer cells) the effects in the human cells were often more outspoken than the murine alternative. In addition, we found the NSC from each species to be more sensitive to IONP exposure than the cell lines.

The observed variations in cell responses can be explained in several possible ways. One may argue that variations in NP uptake in the various cell types will be an important factor. In this regard, dose heterogeneity at single cell level due to variations in NP uptake in the same population will also lead to response heterogeneity [62]. In addition, NP uptake is related to the colloidal stability in the applied cell culture media. Although we did not evaluate the abovementioned parameters in detail, it was previously shown that PMA-coated NPs show good stability in biological media and that they are taken up well by various cell types $[25,63]$. Besides the

Table 2 Cell type-specific nanotoxicity profiles induced by $24 \mathrm{~h}$ exposure to $70 \mathrm{nM}$ IONPs

\begin{tabular}{llllll}
\hline & ROS & $\mathrm{Ca}^{2+}$ & Mitochondria & Cell morphology \\
\cline { 5 - 6 } & & & Area & Circularity \\
\hline hNSC & $\downarrow$ & $\uparrow$ & $\downarrow$ & $\downarrow$ & $\uparrow$ \\
mNSC & $\uparrow$ & $\downarrow$ & $\downarrow$ & $\downarrow$ & $\uparrow$ \\
ReNcell & $\uparrow$ & $\uparrow$ & $\downarrow$ & $\downarrow$ & $\uparrow$ \\
C17.2 & $\downarrow$ & $\uparrow$ & $\downarrow$ & $\downarrow$ & $=$ \\
LA-N-2 & $\downarrow$ & $\downarrow$ & $\downarrow$ & $/$ & $/$ \\
Neuro-2a & $\downarrow$ & $\downarrow$ & $=$ & $\downarrow$ & $\uparrow$ \\
\hline
\end{tabular}

extent of NP uptake, we believe that the cellular response is strongly related to the intracellular NP processing. This will in part depend on the uptake pathway since the latter will co-determine the intracellular trafficking route and the ultimate intracellular location. Indeed, as previously mentioned when NPs are present in the acidic and degrading environment of the endo-lysosomes, stronger cytotoxicity is observed than when the NPs reside in the cytosol [45]. In addition, the variations in intrinsic cell properties, such as the anti-oxidative capacity, metabolic rate (e.g. $\mathrm{Ca}^{2+}$ homeostasis) and mitochondrial activity, are to a large extent accountable for the revealed divergent toxicity profiles. Combined, these elements advocate an in vitro toxicity profiling that takes intrinsic cell properties and variations in the studied cell population into account. Indeed, to understand the intrinsic cellular capacity to traffic and handle exogenous materials could be of key importance to anticipate NP-evoked effects.

Furthermore, our data indicate that it is imperative to apply multiparametric methods that look beyond live/ dead scoring. Notably, even when only minor variations could be detected in the cell viability, as for instance for the Neuro-2a and ReNcells, cellular homeostasis was distinctly altered. In addition, minor cell viability alterations for the ReNcells did not imply that the cell homeostasis was not impaired. Accordingly, Ge et al. [64] found IONPs to evoke important effects on cell function without affecting cell viability. Also, toxicity endpoints included in nanosafety screens should be carefully selected as some are more sensitive or indicative of the induced damage. An example of the latter is the use of cell area and circularity as parameters to describe alterations in cell morphology. Although effects on cell circularity occurred sooner, the impact on cell area was more outspoken and illustrative for the extent of the actual damage in cell types without a complex architecture. Finally, the safety of the coating should be investigated in further detail to determine its possible contribution to some of the observed effects.

Notably, we found that none of the cell types included in this work would be a suitable substitute for any other tested. In contrast, other groups did succeed in identifying a cell line alternative for primary cells based on similar cellular responses to NP exposure [12]. In such cases the use of those cell lines should be encouraged. However, the generalized use of cell lines should be approached with caution, especially when performing a detailed toxicity profiling to elucidate the mechanisms via which NPs alter cell homeostasis. Indeed, cell lines are not always ideal candidates for the analysis of cell function and may not be representative in terms of discrete cell perturbation [19]. Thus, it would be fitting to select a cell type based on the expected exposure and/or 
intended application of the NPs. We also propose to cautiously apply non-human cell types since we, as well as several other groups, have observed notable interspecies variations $[15,16]$.

For screening purposes the selection of a proper cell type is a balancing act. Indeed, primary cells can suffer from several drawbacks like an often limited availability, specific cultivation requirements, a limited life-span, and possible inter-batch and individual variations, which possibly limit the throughput $[7,12]$. Hence, cell lines are still the preferred candidates when performing a largescale screening of numerous NPs. For this reason and because it is highly unlikely that one single cell type will emerge as a universal model, we strongly believe that the definition of a set of standard cell lines would constitute a definite asset in standardizing nanosafety assessments. Additionally, the use of multiple cell types should be encouraged as it was shown to enhance the predictive power of in vitro nanosafety assessments [65]. The selected cell types would preferably be known to mimic responses observed in primary cells and would ideally be thoroughly characterized in terms of their intrinsic properties in order to enhance our understanding of the NPinduced effects.

\section{Conclusions}

In this work, we investigated the effect of both species and cell type related variations on NP-evoked responses in six related neural cell types via a multiparametric approach. Interestingly, the observed impact on cellular health varied widely in each cell type in terms of both the nature and extent of the analyzed effects and cell typespecific nanotoxicity profiles were obtained. Hence, conclusions on the safety of a NP should preferably not be based on the evaluation of a single toxicity end point in a single cell type. We propose to rationally select a cell model based on the envisioned (biomedical) application and/or exposure scenario, especially when performing an extensive in vitro toxicity assessment with the aim of unveiling mechanisms via which the NPs inflict cell injury. Finally, with regard to standardization of in vitro nanosafety evaluations, we strongly believe that for the safety screening of large sets of nanomaterials the selection of a set of standard cell types, representing relevant target tissues, would contribute to the generation of more consistent nanosafety data.

\section{Methods}

\section{NP synthesis and characterization}

AuNPs, AgNPs and IONPs were synthesized and coated with the polymer poly(isobutylene-alt-maleic anhydride) grafted with dodecylamine (PMA), as described in Additional file 1 . Following synthesis, the core diameter was measured using transmission electron microscopy. UV/ Vis spectroscopy was applied to evaluate the spectral characteristics of the NPs. With the combination of UV/ Vis spectroscopy and inductively coupled plasma mass spectrometry the concentrations of the dispersions were determined. Finally the hydrodynamic diameter and zeta-potential were measured using a Zetasizer Nano ZS (Malvern Instruments). Detailed information on the characterization procedures is provided in Additional file 1.

\section{Cell culture}

All assays were performed on six neural cell types (Table 1): human and murine neural stem cells (hNSC and mNSC, Invitrogen and Millipore, Belgium), a human and mouse-derived progenitor cell line, respectively ReNcell (Millipore, Belgium) and C17.2 (Sigma, Belgium), and finally a human neuroblastoma cell line (LA$\mathrm{N}-2$, European Collection of Cell Cultures) as well as a murine counterpart (Neuro-2a, Sigma, Belgium). All cell types were cultured according to the supplier's guidelines. Detailed information on the applied coatings and culture media compositions can be found in Additional file 1.

The cells were cultured at $37^{\circ} \mathrm{C}$ in a humidified atmosphere completed with $5 \% \mathrm{CO}_{2}$. Cell medium was renewed every other day and cells were split after reaching $80 \%$ confluency. Hereto, the cells were dissociated with $0.05 \%$ trypsin-EDTA (Invitrogen, Belgium), after which the cells were centrifuged ( $4 \mathrm{~min}, 300 \mathrm{~g}$ ), resuspended in fresh culture medium and seeded at appropriate densities.

\section{Acute toxicity}

All cell types were seeded at 25,000 cells per well in opaque 96-well plates and were allowed to settle overnight. Thereafter the cells were incubated with $2.5,5,10$, 25, 50 and $100 \mathrm{nM}$ of the AuNPs and AgNPs and 3.5, 7, $14,35,70$ and $140 \mathrm{nM}$ of the IONPs during $24 \mathrm{~h}$ at $37^{\circ} \mathrm{C}$ $\left(5 \% \mathrm{CO}_{2}\right)$. After $24 \mathrm{~h} \mathrm{NP}$ incubation, the CellTiter-GLO ${ }^{\circledR}$ assay (Promega, Belgium) was performed according to the manufacturer's instructions. In short, $100 \mu \mathrm{L}$ of the assay buffer was added to each well. Plates were shaken during 2 min after which a 10-min incubation period was respected. Finally, the signal was measured using a Glo$\operatorname{Max}^{\circledR} 96$ Microplate Luminometer (Promega, Belgium). Experiments were performed in triplicate and the data are represented as the mean \pm the standard error to the mean (SEM).

\section{High content imaging}

For the multiparametric analysis, cells were seeded in 24-well plates and were allowed to attach overnight. Optimal seeding cell densities were identified for each cell type individually. The optimal seeding density was 
Table 3 Seeding densities and incubation volumes per well applied in the multiparametric analysis

\begin{tabular}{lrrrrrr}
\hline & hNSC & mNSC & ReNcell & C17.2 & LA-N-2 & Neuro-2a \\
\hline Cell density & 35,000 & 17,500 & 17,500 & 15,000 & 50,000 & 15,000 \\
Volume $(\mu \mathrm{L})$ & 700 & 350 & 350 & 300 & 1000 & 300 \\
\hline
\end{tabular}

defined as the density that would result in an $80 \%$ confluent cell layer in the untreated control at the end point of the assay. In order to preserve the cell density/cell medium volume ratio for all cell types, we varied the latter according to the optimal cell seeding density (Table 3 ).

For the evaluation of effects on ROS production and $\left[\mathrm{Ca}^{2+}\right]_{\mathrm{c}} 7,14,35,70$ and $140 \mathrm{nM}$ IONP dispersions were applied, whereas for the effects on cell morphology and the mitochondria $3.5,7,14,35$ and $70 \mathrm{nM}$ were tested as effects on cell function were expected to occur starting from lower NP doses. As the volume of cell medium used for incubation was adjusted according to the cell density, the NP number/volume cell medium/cell number remained equal in all high content experiments. Similar to acute toxicity experiments, the cells were incubated with the IONPs during $24 \mathrm{~h}$ at $37{ }^{\circ} \mathrm{C}$ in an atmosphere containing $5 \% \mathrm{CO}_{2}$ after which staining and analysis were performed. This set of data is presented as mean \pm SEM from to independent replicates.

\section{Reactive oxygen species and cytoplasmic calcium levels}

To allow detection of reactive oxygen species (ROS) the general ROS marker CellROX ${ }^{\circledR}$ green probe (Molecular Probes, Invitrogen, Belgium) was selected. The latter was combined with the Rhod-2 AM (Molecular Probes, Invitrogen, Belgium), which becomes strongly fluorescent upon interaction with free $\mathrm{Ca}^{2+}$ in the cytoplasm. Following $24 \mathrm{~h}$ IONP incubation, the cells were labelled with both probes as described in Additional file 1.

\section{Effect on mitochondrial health and cell morphology}

The mitochondria were labelled with Mitotracker ${ }^{\circledR}$ CMX-ROS Red (Molecular Probes, Invitrogen, Belgium), which specifically accumulates in the mitochondria based on its membrane potential. To allow evaluation of cell morphology the HCS CellMask ${ }^{\mathrm{TM}}$ Blue probe (Molecular Probes, Invitrogen, Belgium) was applied. Again, cells were labeled following $24 \mathrm{~h}$ of IONP exposure as explained in Additional file 1.

\section{Statistics}

Acute toxicity data are expressed as mean $\pm \operatorname{SEM}(n=3)$. IN Cell data are presented as mean values normalized against the untreated control $\pm \operatorname{SEM}(\mathrm{n}=2)$. Statistical analysis was performed using one-way ANOVA combined with post hoc Dunnett test.

\section{Additional file}

Additional file 1. Full methodology on the synthesis and NP-cell interaction studies as well as and additional characterization data on the different NPS.

\begin{abstract}
Abbreviations
$\Delta \Psi_{\mathrm{m}}$ : mitochondrial membrane potential; $\left[\mathrm{Ca}^{2+}\right]_{\mathrm{c}}$ : cytosolic free calcium concentration; AgNPs: silver nanoparticles; ATP: adenosine triphosphate; AuNPs: gold nanoparticles; $\mathrm{Ca}^{2+}$ : calcium; $\mathrm{d}_{c}$ : core diameter; $\mathrm{HCS}$ : high content screening; hNSC: human neural stem cell; IONPS: iron oxide nanoparticles; mNSC: murine neural stem cell; NPs: nanoparticles; NTC: not treated control; PMA: poly(isobutylene-alt-maleic anhydride); ROS: reactive oxygen species; SEM: standard error of the mean; $\mathrm{TiO}_{2}$ NPS: titanium dioxide nanoparticles.
\end{abstract}

\section{Authors' contributions}

FJ, SJS and KR designed the study and the in vitro assays were performed by FJ. DV was responsible for NP synthesis and characterization under the supervision of WJP and BP. SJS and BBM aided with the initiation of the IN Cell experiments. SCDS and KR provided supervision and guidance throughout this work. The manuscript was written through contributions of all authors and all authors approved the final version of the manuscript. All authors read and approved the final manuscript.

\section{Author details}

${ }^{1}$ Lab of General Biochemistry and Physical Pharmacy, Department of Pharmaceutics, Faculty of Pharmaceutical Sciences, Ghent University, Ottergemsesteenweg 460, 9000 Ghent, Belgium. ${ }^{2}$ Department of Physics, Philipps University of Marburg, Renthof 7, 35037 Marburg, Germany. ${ }^{3}$ Biomedical MRI Unit/MoSAIC, Department of Medicine, KULeuven, Herestraat 49, 3000 Louvain, Belgium.

\section{Acknowledgements}

We would like to thank Shareen Doak from the DNA damage group, Institute of Life Sciences, Swansea University, UK for the use of the IN Cell Analyzer 2000. Additionally we wish to thank Sebastian Munck and Nicky Corthout from the VIB Centre for Biology of Disease, Belgium for the technical guidance in the use of the IN Cell Analyzer 2000 and IN Cell Developer Toolbox software. We would also like to thank Tianqiang Wang for support in nanoparticle characterization and Karsten Kantner for the ICP measurements.

\section{Competing interests}

The authors declare that they have no competing interests.

\section{Availability of data and material}

All data generated or analysed during this study are included in this published article and its Additional file 1.

\section{Funding}

FJ is a doctoral fellow of the Agency for Innovation by Science and Technology in Flanders (IWT). KR and SJS are postdoctoral fellows of the Research Foundation-Flanders (FWO). Funding of both agencies was applied to design, perform and analyze all cell-based experiments. The DFG Germany (GRK 1782 to WJP), the European Commission (grant FutureNanoNeeds to WJP) and Alexander von Humboldt Foundation (postdoctoral fellowship of BP) supported the NP synthesis and characterization part of this work.

Received: 10 June 2016 Accepted: 26 August 2016

Published online: 09 September 2016 


\section{References}

1. Stark WJ, Stoessel PR, Wohlleben W, Hafner A. Industrial applications of nanoparticles. Chem Soc Rev. 2015;44:5793-805.

2. Lim EK, Kim T, Paik S, Haam S, Huh YM, Lee K. Nanomaterials for theranostics: recent advances and future challenges. Chem Rev. 2015;115:327-94.

3. Haase A, Rott S, Mantion A, Graf P, Plendl J, Thunemann AF, Meier WP, Taubert A, Luch A, Reiser G. Effects of silver nanoparticles on primary mixed neural cell cultures: uptake, oxidative stress and acute calcium responses. Toxicol Sci. 2012;126:457-68.

4. Min Y, Caster JM, Eblan MJ, Wang AZ. Clinical translation of nanomedicine. Chem Rev. 2015:115:11147-90.

5. Rivera-Gil P, De Aberasturi DJ, Wulf V, Pelaz B, Del Pino P, Zhao YY, De La Fuente JM, De Larramendi IR, Rojo T, Liang XJ, Parak WJ. The challenge to relate the physicochemical properties of colloidal nanoparticles to their cytotoxicity. Acc Chem Res. 2013;46:743-9.

6. Nel A, Xia T, Madler L, Li N. Toxic potential of materials at the nanolevel. Science. 2006;311:622-7.

7. Joris F, Manshian BB, Peynshaert K, De Smedt SC, Braeckmans K, Soenen SJ. Assessing nanoparticle toxicity in cell-based assays: influence of cell culture parameters and optimized models for bridging the in vitro-in vivo gap. Chem Soc Rev. 2013;42:8339-59.

8. Jan E, Byrne SJ, Cuddihy M, Davies AM, Volkov Y, Gun'ko YK, Kotov NA. High-content screening as a universal tool for fingerprinting of cytotoxicity of nanoparticles. ACS Nano. 2008;2:928-38.

9. George S, Pokhrel S, Xia T, Gilbert B, Ji Z, Schowalter M, Rosenauer A, Damoiseaux R, Bradley KA, Madler L, Nel AE. Use of a rapid cytotoxicity screening approach to engineer a safer zinc oxide nanoparticle through iron doping. ACS Nano. 2010;4:15-29.

10. Ong KJ, MacCormack TJ, Clark RJ, Ede JD, Ortega VA, Felix LC, Dang MK, Ma G, Fenniri H, Veinot JG, Goss GG. Widespread nanoparticle-assay interference: implications for nanotoxicity testing. PLoS ONE. 2014;9:e90650.

11. Feliu N, Pelaz B, Zhang Q, del Pino P, Nyström A, Parak WJ. Nanoparticle dosage-a nontrivial task of utmost importance for quantitative nanotoxicology. WIREs Nanomed Nanobiotechnol. 2015.

12. Kermanizadeh A, Lohr M, Roursgaard M, Messner S, Gunness P, Kelm JM, Moller P, Stone V, Loft S. Hepatic toxicology following single and multiple exposure of engineered nanomaterials utilising a novel primary human 3D liver microtissue model. Part Fibre Toxicol. 2014;11:56.

13. Wang J, Fang $X$, Liang W. Pegylated phospholipid micelles induce endoplasmic reticulum-dependent apoptosis of cancer cells but not normal cells. ACS Nano. 2012;6:5018-30

14. Bregoli L, Chiarini F, Gambarelli A, Sighinolfi G, Gatti AM, Santi P, Martelli AM, Cocco L. Toxicity of antimony trioxide nanoparticles on human hematopoietic progenitor cells and comparison to cell lines. Toxicology. 2009;262:121-9.

15. Zhang $\mathrm{H}$, Wang $X$, Wang $M$, Li L, Chang $C H$, Ji Z, Xia T, Nel AE. Mammalian cells exhibit a range of sensitivities to silver nanoparticles that are partially explicable by variations in antioxidant defense and metallothionein expression. Small. 2015;11:3797-805.

16. Luengo Y, Nardecchia S, Morales MP, Serrano MC. Different cell responses induced by exposure to maghemite nanoparticles. Nanoscale. 2013;5:11428-37

17. Mukherjee SG, O'Claonadh N, Casey A, Chambers G. Comparative in vitro cytotoxicity study of silver nanoparticle on two mammalian cell lines. Toxicol In Vitro. 2012;26:238-51.

18. Wang Y, Aker WG, Hwang HM, Yedjou CG, Yu H, Tchounwou PB. A study of the mechanism of in vitro cytotoxicity of metal oxide nanoparticles using catfish primary hepatocytes and human HepG2 cells. Sci Total Environ. 2011;409:4753-62.

19. Ekstrand-Hammarstrom B, Akfur CM, Andersson PO, Lejon C, Osterlund $L$, Bucht A. Human primary bronchial epithelial cells respond differently to titanium dioxide nanoparticles than the lung epithelial cell lines A549 and BEAS-2B. Nanotoxicology. 2012;6:623-34.

20. Kermanizadeh A, Gaiser BK, Ward MB, Stone V. Primary human hepatocytes versus hepatic cell line: assessing their suitability for in vitro nanotoxicology. Nanotoxicology. 2013;7:1255-71.

21. Shen WB, Vaccaro DE, Fishman PS, Groman EV, Yarowsky P. SIRB, sans iron oxide rhodamine $\mathrm{B}$, a novel cross-linked dextran nanoparticle, labels human neuroprogenitor and SH-SY5Y neuroblastoma cells and serves as a USPIO cell labeling control. Contrast Media Mol Imaging. 2016;11:222-8.
22. Soenen SJ, Himmelreich U, Nuytten N, De Cuyper M. Cytotoxic effects of iron oxide nanoparticles and implications for safety in cell labelling. Biomaterials. 2011;32:195-205.

23. Lei H, Nan X, Wang Z, Gao L, Xie L, Zou C, Wan Q, Pan D, Beauchamp N, Yang $X$, et al. Stem cell labeling with superparamagnetic iron oxide nanoparticles using focused ultrasound and magnetic resonance imaging tracking. J Nanosci Nanotechnol. 2015:15:2605-12.

24. Hahn MA, Singh AK, Sharma P, Brown SC, Moudgil BM. Nanoparticles as contrast agents for in vivo bioimaging: current status and future perspectives. Anal Bioanal Chem. 2011;399:3-27.

25. Manshian BB, Moyano DF, Corthout N, Munck S, Himmelreich U, Rotello VM, Soenen SJ. High-content imaging and gene expression analysis to study cell-nanomaterial interactions: the effect of surface hydrophobicity. Biomaterials. 2014;35:9941-50.

26. Wu YY, Mujtaba T, Rao MS. Isolation of stem and precursor cells from fetal tissue. Methods Mol Biol. 2002;198:29-40.

27. Donato R, Miljan EA, Hines SJ, Aouabdi S, Pollock K, Patel S, Edwards FA, Sinden JD. Differential development of neuronal physiological responsiveness in two human neural stem cell lines. BMC Neurosci. 2007;8:36.

28. Seeger RC, Rayner SA, Banerjee A, Chung H, Laug WE, Neustein $H B$, Benedict WF. Morphology, growth, chromosomal pattern, and fibrinolytic-activity of 2 new human neuroblastoma cell lines. Cancer Res. 1977:37:1364-71.

29. Ryder EF, Snyder EY, Cepko CL. Establishment and characterization of multipotent neural cell-lines using retrovirus vector-mediated oncogene transfer. J Neurobiol. 1990;21:356-75.

30. Klebe RJ, Ruddle RH. Neuroblastoma-cell culture analysis of a differentiating stem cell system. J Cell Biol. 1969;43:A69.

31. Lin CA, Sperling RA, Li JK, Yang TY, Li PY, Zanella M, Chang WH, Parak WJ. Design of an amphiphilic polymer for nanoparticle coating and functionalization. Small. 2008;4:334-41.

32. Sun S, Zeng H, Robinson DB, Raoux S, Rice PM, Wang SX, Li G. Monodisperse $\mathrm{MFe}_{2} \mathrm{O}_{4}(\mathrm{M}=\mathrm{Fe} \mathrm{Co}, \mathrm{Mn}$ ) nanoparticles. J Am Chem Soc. 2004;126:273-9.

33. Caballero-Diaz E, Pfeiffer C, Kastl L, Rivera-Gil P, Simonet B, Valcarcel M, Jimenez-Lamana J, Laborda F, Parak WJ. The toxicity of silver nanoparticles depends on their uptake by cells and thus on their surface chemistry. Part Part Syst Charact. 2013;30:1079-85.

34. Soenen SJ, Parak WJ, Rejman J, Manshian B. (Intra)cellular stability of inorganic nanoparticles: effects on cytotoxicity, particle functionality, and biomedical applications. Chem Rev. 2015;115:2109-35.

35. Soenen SJ, Rivera-Gil P, Montenegro JM, Parak WJ, De Smedt SC, Braeckmans K. Cellular toxicity of inorganic nanoparticles: common aspects and guidelines for improved nanotoxicity evaluation. Nano Today. 2011;6:446-65

36. Wilkinson KE, Palmberg L, Witasp E, Kupczyk M, Feliu N, Gerde P, Seisenbaeva GA, Fadeel B, Dahlen SE, Kessler VG. Solution-engineered palladium nanoparticles: model for health effect studies of automotive particulate pollution. ACS Nano. 2011;5:5312-24.

37. Schlinkert P, Casals E, Boyles M, Tischler U, Hornig E, Tran N, Zhao JY, Himly M, Riediker M, Oostingh GJ, et al. The oxidative potential of differently charged silver and gold nanoparticles on three human lung epithelial cell types. J Nanobiotechnol. 2015:13:1.

38. George S, Xia T, Rallo R, Zhao Y, Ji Z, Lin S, Wang X, Zhang H, France B, Schoenfeld $D$, et al. Use of a high-throughput screening approach coupled with in vivo zebrafish embryo screening to develop hazard ranking for engineered nanomaterials. ACS Nano. 2011;5:1805-17.

39. Park EJ, Park K. Oxidative stress and pro-inflammatory responses induced by silica nanoparticles in vivo and in vitro. Toxicol Lett. 2009;184:18-25.

40. Zhang H, Pokhrel S, Ji Z, Meng H, Wang X, Lin S, Chang CH, Li L, Li R, Sun $B$, et al. PdO doping tunes band-gap energy levels as well as oxidative stress responses to a $\mathrm{Co}(3) \mathrm{O}(4) \mathrm{p}$-type semiconductor in cells and the lung. J Am Chem Soc. 2014;136:6406-20.

41. Sharma G, Kodali V, Gaffrey M, Wang W, Minard KR, Karin NJ, Teeguarden $J G$, Thrall BD. Iron oxide nanoparticle agglomeration influences dose rates and modulates oxidative stress-mediated dose-response profiles in vitro. Nanotoxicology. 2014;8:663-75.

42. Fujioka K, Hanada S, Inoue Y, Sato K, Hirakuri K, Shiraishi K, Kanaya F, Ikeda K, Usui R, Yamamoto K, et al. Effects of silica and titanium oxide particles on a human neural stem cell line: morphology, mitochondrial 
activity, and gene expression of differentiation markers. Int J Mol Sci. 2014;15:11742-59.

43. Huang DM, Hsiao JK, Chen YC, Chien LY, Yao M, Chen YK, Ko BS, Hsu SC, Tai LA, Cheng HY, et al. The promotion of human mesenchymal stem cell proliferation by superparamagnetic iron oxide nanoparticles. Biomaterials. 2009;30:3645-51.

44. Gao L, Zhuang J, Nie L, Zhang J, Zhang Y, Gu N, Wang T, Feng J, Yang D, Perrett S, Yan X. Intrinsic peroxidase-like activity of ferromagnetic nanoparticles. Nat Nanotechnol. 2007;2:577-83.

45. Sabella S, Carney RP, Brunetti V, Malvindi MA, Al-Juffali N, Vecchio G, Janes SM, Bakr OM, Cingolani R, Stellacci F, Pompa PP. A general mechanism for intracellular toxicity of metal-containing nanoparticles. Nanoscale. 2014;6:7052-61.

46. Petters C, Thiel K, Dringen R. Lysosomal iron liberation is responsible for the vulnerability of brain microglial cells to iron oxide nanoparticles: comparison with neurons and astrocytes. Nanotoxicology. 2016;10:332-42.

47. Zhivotovsky B, Orrenius S. Calcium and cell death mechanisms: a perspective from the cell death community. Cell Calcium. 2011;50:211-21.

48. Clapham DE. Calcium signaling. Cell. 2007;131:1047-58.

49. Ariano P, Zamburlin P, Gilardino A, Mortera R, Onida B, Tomatis M, Ghiazza M, Fubini B, Lovisolo D. Interaction of spherical silica nanoparticles with neuronal cells: size-dependent toxicity and perturbation of calcium homeostasis. Small. 2011;7:766-74.

50. Tseng YC, Yang A, Huang L. How does the cell overcome Icp nanoparticle-induced calcium toxicity? Mol Pharm. 2013;10:4391-5.

51. Anguissola S, Garry D, Salvati A, O'Brien PJ, Dawson KA. High content analysis provides mechanistic insights on the pathways of toxicity induced by amine-modified polystyrene nanoparticles. PLOS ONE. 2014;9:e108025.

52. Brookes PS, Yoon Y, Robotham JL, Anders MW, Sheu SS. Calcium, ATP, and ROS: a mitochondrial love-hate triangle. Am J Physiol Cell Physiol. 2004;287:C817-33.

53. Capiod T, Shuba Y, Skryma R, Prevarskaya N. Calcium signalling and cancer cell growth. Subcell Biochem. 2007;45:405-27.

54. Fulda S, Galluzzi L, Kroemer G. Targeting mitochondria for cancer therapy. Nat Rev Drug Discov. 2010;9:447-64.
55. Ito K, Suda T. Metabolic requirements for the maintenance of self-renewing stem cells. Nat Rev Mol Cell Biol. 2014;15:243-56.

56. Gottlieb E, Armour SM, Harris MH, Thompson CB. Mitochondrial membrane potential regulates matrix configuration and cytochrome $\mathrm{c}$ release during apoptosis. Cell Death Differ. 2003;10:709-17.

57. Heerdt BG, Houston MA, Wilson AJ, Augenlicht LH. The intrinsic mitochondrial membrane potential (Deltapsim) is associated with steadystate mitochondrial activity and the extent to which colonic epithelial cells undergo butyrate-mediated growth arrest and apoptosis. Cancer Res. 2003;63:6311-9.

58. Buyukhatipoglu K, Clyne AM. Superparamagnetic iron oxide nanoparticles change endothelial cell morphology and mechanics via reactive oxygen species formation. J Biomed Mater Res A. 2011;96:186-95.

59. Tay CY, Cai P, Setyawati MI, Fang W, Tan LP, Hong CH, Chen X, Leong DT. Nanoparticles strengthen intracellular tension and retard cellular migration. Nano Lett. 2014;14:83-8.

60. Wu YL, Putcha N, Ng KW, Leong DT, Lim CT, Loo SCJ, Chen XD. Biophysical responses upon the interaction of nanomaterials with cellular interfaces. Acc Chem Res. 2013;46:782-91.

61. Soenen SJ, Manshian B, Montenegro JM, Amin F, Meermann B, Thiron T, Cornelissen M, Vanhaecke F, Doak S, Parak WJ, et al. Cytotoxic effects of gold nanoparticles: a multiparametric study. ACS Nano. 2012;6:5767-83.

62. Ware MJ, Godin B, Singh N, Majithia R, Shamsudeen S, Serda RE, Meissner $K E$, Rees $P$, Summers HD. Analysis of the influence of cell heterogeneity on nanoparticle dose response. ACS Nano. 2014;8:6693-700.

63. Kirchner C, Liedl T, Kudera S, Pellegrino T, Javier AM, Gaub HE, Stolzle S, Fertig N, Parak WJ. Cytotoxicity of colloidal CdSe and CdSe/ZnS nanoparticles. Nano Lett. 2005;5:331-8.

64. Ge GY, Wu HF, Xiong F, Zhang Y, Guo ZR, Bian ZP, Xu JD, Gu CR, Gu N, Chen $X J$, Yang D. The cytotoxicity evaluation of magnetic iron oxide nanoparticles on human aortic endothelial cells. Nanoscale Res Lett. 2013;8:1.

65. Shaw SY, Westly EC, Pittet MJ, Subramanian A, Schreiber SL, Weissleder R. Perturbational profiling of nanomaterial biologic activity. Proc Natl Acad Sci USA. 2008;105:7387-92.

\section{Submit your next manuscript to BioMed Central and we will help you at every step:}

- We accept pre-submission inquiries

- Our selector tool helps you to find the most relevant journal

- We provide round the clock customer support

- Convenient online submission

- Thorough peer review

- Inclusion in PubMed and all major indexing services

- Maximum visibility for your research

Submit your manuscript at www.biomedcentral.com/submit
() Biomed Central 